\title{
The use of infrared thermography for defects detection on reinforced concrete bridges
}

\author{
by H. Cannard*, M. Mahrez*, T. Perrin*, V. Muzet*, D Prybyla*, F.Brachelet ${ }^{* *}$
}
*CEREMA/DTerEst/LR de Strasbourg, 11 rue Jean Mentelin, 67035 Strasbourg, herve.cannard@cerema.fr
** Laboratoire de Génie Civil et géo-Environnement, (LGCgE), PRES Lille Nord de France
Faculté des Sciences Appliquées, Technoparc Futura, 62400 Béthune, France

\begin{abstract}
Early detection of defects in concrete structures, such as bridges or dams, is essential to optimize the maintenance of civil engineering facilities. Optical methods like infrared thermography constitute non-destructive means of control and measurement but they are generally confined in laboratories where both the setup and environment are controlled. This article presents the application of infrared thermography for the outdoor defects detection on different concrete structures and in situ on reinforced concrete bridges.
\end{abstract}

\section{Introduction}

Nowadays, France counts around 200000 bridges that are in use. On the national roads network, there are approximately 12000 bridges corresponding to a 5 million meters square area [1]. The majority of these bridges are made with reinforced concrete (48,6\%) and in prestressed concrete for $18.6 \%$ (Fig. 1). These constructions, dating from the 1970-80, may be subject to some classical pathologies induced by aging, like delamination of the concrete and corrosion of the reinforcing steel.

In France, the bridges condition evaluation is made according to the IQOA method (Image of the Quality of Construction Works) [2]. After a complete visual inspection, a set of grades is given. Visual inspections require establishing contact with the structure, which in turn raises the issue of operator safety, important costs and disturbances of road traffic on the upper and lower lanes. Optical methods have the advantages of being non-destructive and do not necessitate any human intervention in the area close to the structure, so they can provide a comprehensive visualization of the defects. A successful application of infrared thermography is the evaluation of the bonding quality of the waterproofing layer $[3,4]$. In order to evaluate the potential applicability of IR to the detection of defects, a feasibility study has been carried out in situ with an IR camera on several concrete bridges. To interpret the qualitative results obtained outdoor, a study was made on special designed test slabs.
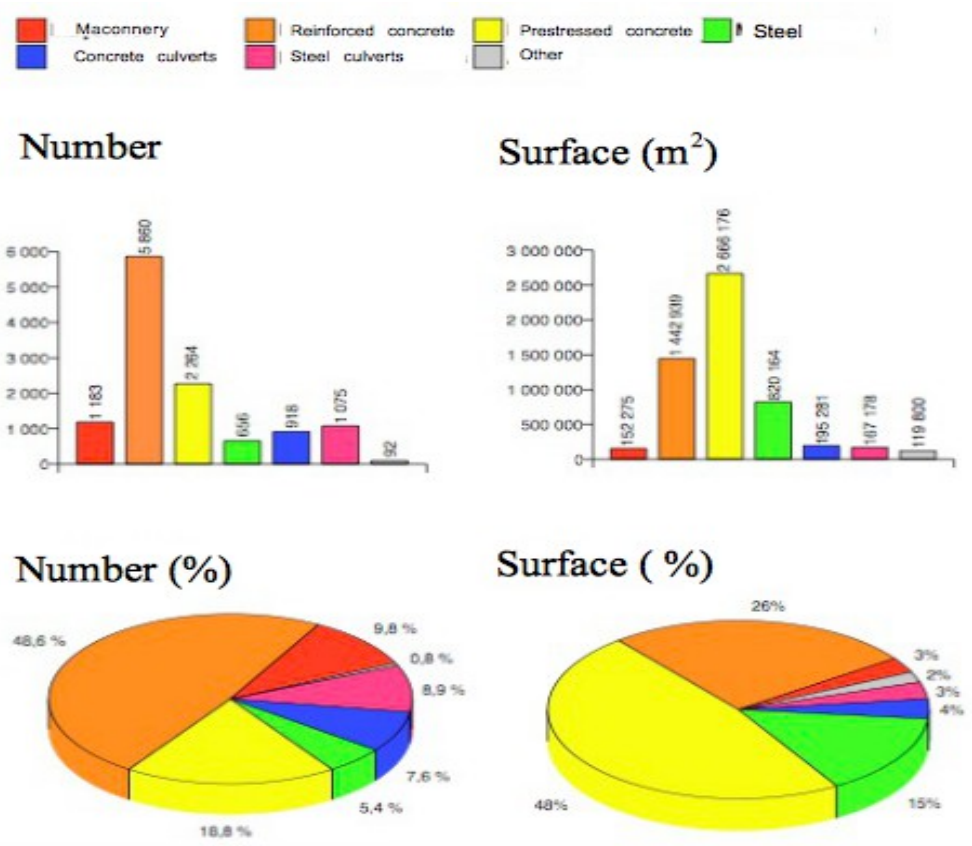

Fig. 1 : Bridge inventory by category on the French national roads network. 


\section{Summary of disorders found on cornices of bridges and introduction of the defect detection methodology}

\subsection{Origins of delamination in concrete cornices of bridges}

Reinforced concrete uses steel to provide strength to tensile that are needed in structural concrete. It prevents the failure of concrete structures which are subjected to tensile and flexural stresses due to traffic, winds, dead loads and thermal cycling.

The common defects identified on concrete bridges by visual inspection are delamination of concrete and corrosion of reinforcing steel [5]. On aging bridges, a particularly important point to monitor is the integrity of the concrete covering on the outer surfaces of cornices and on the horizontal surfaces below the deck (Fig. 2). Serious accidents may occur if pieces of concrete fall on the road.

Fig. 3 shows the corrosion process. Aggressive agents like chlorides enter the concrete and modify its chemical properties. The passivation of steel is no longer guaranteed and initiation of corrosion begins. When steel corrodes, the resulting rust occupies a greater volume than the steel and leads to a loss of bond between the steel and the concrete. This expansion creates tensile stresses in the concrete, which can eventually cause cracking, delamination, and spalling. If left unchecked, the integrity and the durability of the structure can be affected.

The first defense against corrosion of steel in bridges is the quality of the concrete coverage over the reinforcing bars. Concrete has to slow down the penetration of chloride salts and the development of carbonation. Degraded concrete and thin cover (caused by freezing and thawing damage for example) can accelerate this penetration.
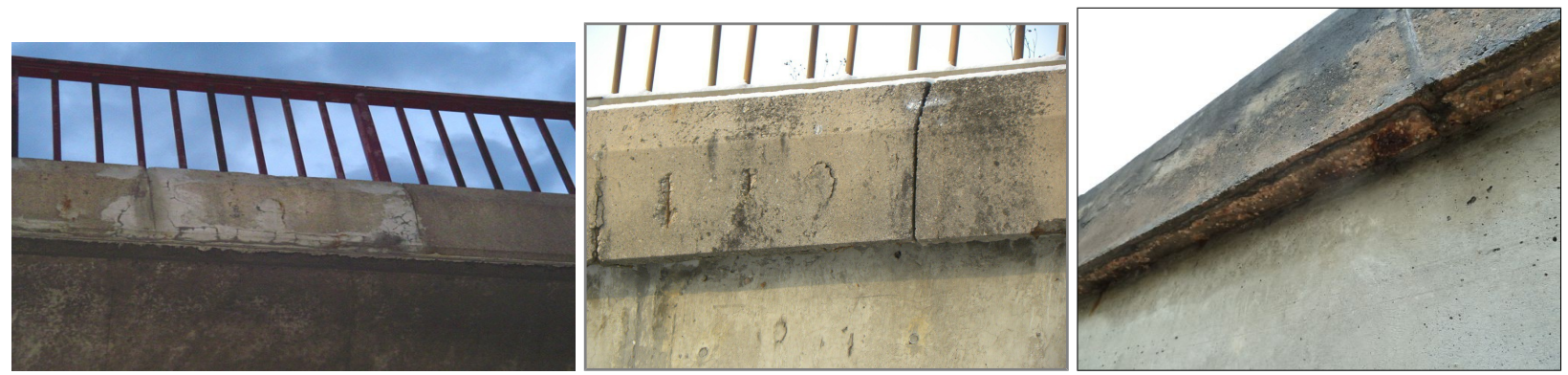

Fig. 2. Samples of steel corrosion and spalling of concrete on concrete cornices

a)

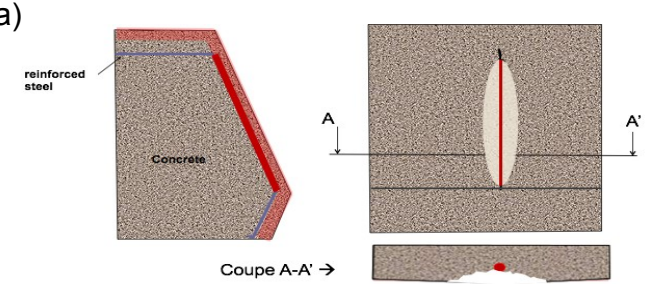

b)

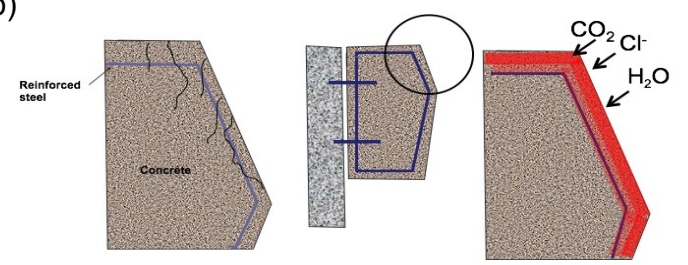

Fig. 3. Process of steel corrosion and spalling of concrete. a) Penetration of aggressive agents, b) Spalling of concrete and initialization of corrosion

\subsection{Application of infrared thermography to the detection of delamination}

The major goal of this study is to detect the delamination on cornices with infrared thermography. If subjected to the same thermal stimulation, a cornice with defect presents surface temperatures that differ from a cornice without defect. Considering the cornice as a thermal system, the presence of a defect like an air gap introduces a supplementary thermal resistance [6]. Since the thermal conductivity of air is inferior to the thermal conductivity of the concrete and the steel, a thermal gradient can be generated and recorded with an infrared camera. This phenomenon is time dependent and can be helpful to reveal defects. The heat flow depends on the temperature difference and is disrupted as soon as it crosses a beginning of spalling or a cracked area (Fig. 4). For instance after a sunny day, when the bridge is warmer than the surroundings, the defects could appear colder than the surrounded intact area.

All the investigations conducted on the bridge are based on the standard ASTM D4788 [7]. 


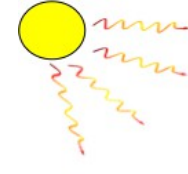

a)

Direction of heat flow

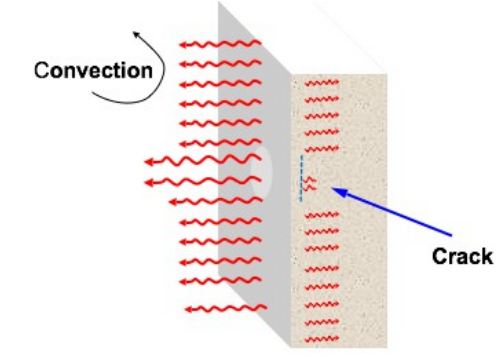

Fig. 4. Direction of heat flow: a) by day, b) by night

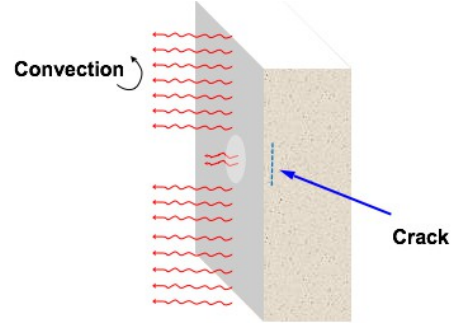

4 Direction of heat flow

The camera used in this study is an uncooled model FLIR S640 with a 640x480 micro bolometers IRFPA with a NETD of $30 \mathrm{mK}$ operating in the LWIR (7 to 15 micrometers). A standard camera lens $\left(24^{\circ} \times 18^{\circ}\right)$ and a telephoto lens $\left(12^{\circ} \times 9^{\circ}\right)$ were used. This apparatus is well adapted to the outdoor conditions because its spectral sensitivity is far from the solar spectra. With this setup, it is possible to have simultaneously visible and infrared images.

\section{Feasability experimentations on bridges cornices}

\subsection{Experiment in situ}

A first test was conducted on a reinforced concrete bridge which had some apparent defects (Fig. 5a). The aim of this first trial was to evaluate the thermal images quality under natural solicitation for different meteorological conditions. The experiment has shown that it was possible to detect the bridge defects under natural environmental stimulation [8], the defects appearing warmer than the intact surrounding area (Fig. 5b).

a)

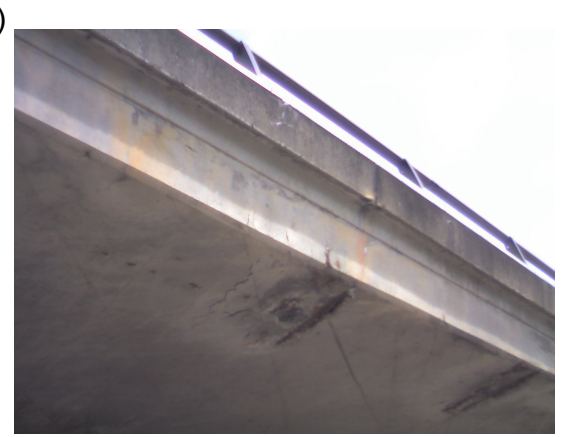

b)

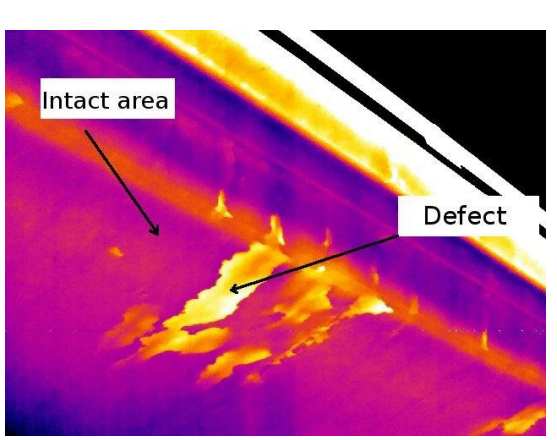

Fig. 5. Images in the visible spectrum (a) and in the infrared spectrum (b) of a concrete bridge deck.

\subsection{Experiment on a sample of bridge cornice}

The second experiment was conducted outdoor on a sample of a bridge cornice subjected to natural stimulation. The sample presented four interesting areas:

- $\quad$ area 1 : release of burst of concrete remaining in place,

- $\quad$ area 2 : partial detachment of a burst,

- $\quad$ area 3 : total separation of a burst,

- $\quad$ area 4 : intact part of reinforced concrete (reference). 
a)

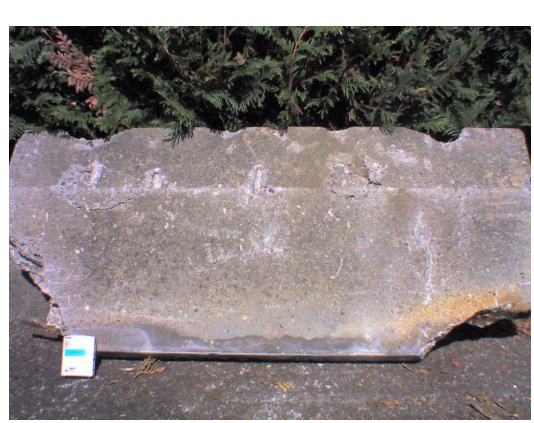

b)

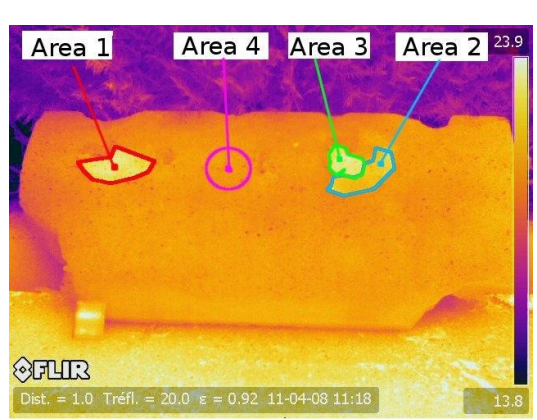

c)

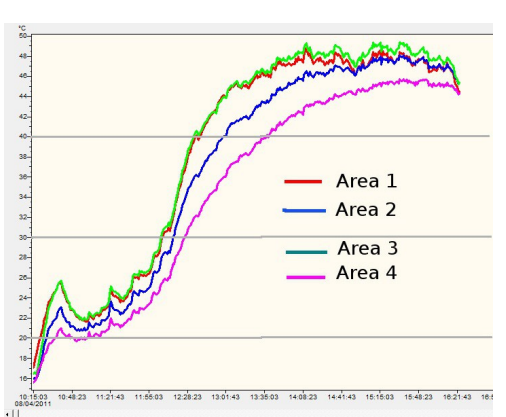

Fig. 6. Image of the sample of a bridge (a)

(a), infrared image with the 4 tested areas

(b), mean temperature as a function of time for the 4 tested areas (c).

The temperature evolution of the sample was recorded during one day for the four defined areas. All the defects were detected (Fig. 6b). During the sunshine period, the temperature difference between the intact part and the area with the defects was greater than $1 \mathrm{~K}$ and could reach $7 \mathrm{~K}$, which is higher than the thermal sensitivity of the infrared camera $(\mathrm{NETD}=30 \mathrm{mK})$.

This qualitative evaluation has shown the feasibility of detecting disorders in reinforced concrete by infrared thermography under external condition. A quantitative evaluation of the defects could be useful to evaluate, for instance, the surface of concrete affected by defects.

\section{Evaluation of quantitative infrared thermography}

\subsection{Description of test slabs}

To simulate delamination defect of concrete, test slabs were realised with known defects. These specimens have been made with cement mortar (thermal conductivity $=1.60 \mathrm{~W} \mathrm{~m}^{-10} \mathrm{C}$ ). In each blocks, three defects where created with polystyrene foam (thermal conductivity $=0.04 \mathrm{~W} \mathrm{~m}^{-1} \mathrm{C}$ ) and placed at 1,2 and $4 \mathrm{~cm}$ deep from the external surface. These defects, shown in Fig. 7, are circular, rectangular or square shapes.

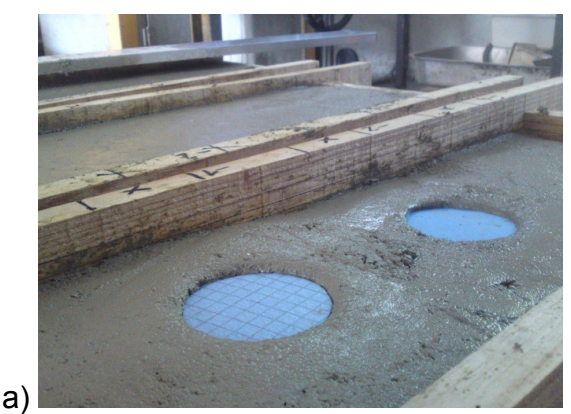

b)

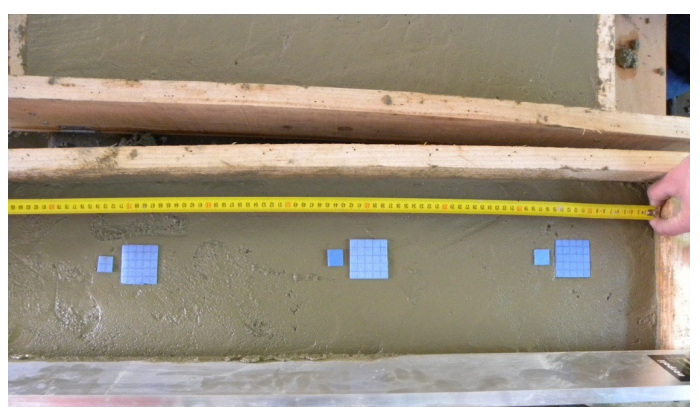

Fig. 7. Positioning of the defects during the pouring of the specimen: a) circular defects, b) square defects.

\subsection{Modeling of test slabs}

In order to evaluate the thermal evolution of the samples under external conditions, a model has been build. A cornice is modeled by a rectangle of concrete with a size of $50 \times 20 \mathrm{~cm}$. The defect is simulated by an air gap with a size of $0.2 \times 8 \mathrm{~cm}$ at depth of 2 and $4 \mathrm{~cm}$ as illustrated on Fig. 8a. Thermophysical parameters are shown in table Fig. 8b.

The objective of this simulation is to determine the evolution of the surface temperature gradient. The rear face of the cornice is considered to be at a fixed temperature of $T_{\text {back }}=10^{\circ} \mathrm{C}$. The exchanges between the front face and the surrounding fluid at $T_{\text {air }}=10^{\circ} \mathrm{C}$ are represented by a global coefficient of exchange $\left(h_{g}=15 \mathrm{~W} / \mathrm{m}^{2}\right.$.C). Boundary conditions imposed on the sides of the beam are of adiabatic type. 


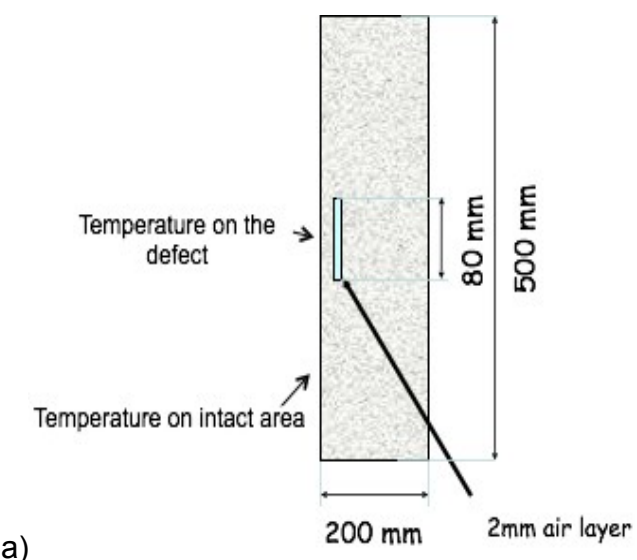

The model result with different simulation conditions is illustrated in Fig. 9. It shows that:

- the amplitude of the signal must be sufficiently high so that the effect on the surface is detectable ;

- the ratio between the defect size and its proximity to the surface should be large enough to create a thermal contrast ;

- $\quad$ propagation of sinusoidal heat waves is exponentially attenuated as a function of depth (Fig. 10b).

a)

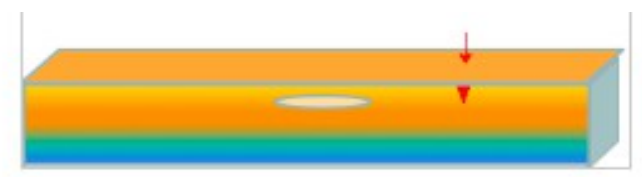

b)

\begin{tabular}{l|c|c|c|}
\hline Material & $\lambda$ & $\rho$ & $\mathrm{c}$ \\
\hline Air & 0.0242 & 1.2 & 1006 \\
Concrete & 1.6 & 2300 & 820 \\
\hline
\end{tabular}

$\lambda$ : thermal conductivity $[\mathrm{W} / \mathrm{m} . \mathrm{K}]$

$\rho:$ density $\left[\mathrm{kg} / \mathrm{m}^{3}\right]$

c : specific heat $[\mathrm{J} / \mathrm{kg} . \mathrm{K}]$

Fig. 8. a) Model of the cornice, b) Thermophysical parameters of the modeling

Fig. 9. Effect on surface when amplitude of stimulation is insufficient (a) and sufficient to detect the defect (b)

A sinusoidal heat flow of $+/-300 \mathrm{~W} / \mathrm{m}^{2}$ is also simulated on 24 hours (Fig. 10a).

Fig. 10b shows the evolution for 24 hours of the temperature difference between a defect area and an intact one. Amplitude of the resultant temperatures is higher than $1.5^{\circ} \mathrm{C}$ for a defect at a depth of $2 \mathrm{~cm}$ and is less than $1^{\circ} \mathrm{C}$ for $a$ deeper defect at $4 \mathrm{~cm}$.

These results demonstrate that defects localized at a depth of $4 \mathrm{~cm}$ could be detected by infrared thermography. These encouraging results let us think that it is possible to detect the beginning of spalling of cover concrete by an infrared camera, as the concrete cover on aged bridges is roughly $3 \mathrm{~cm}$. 

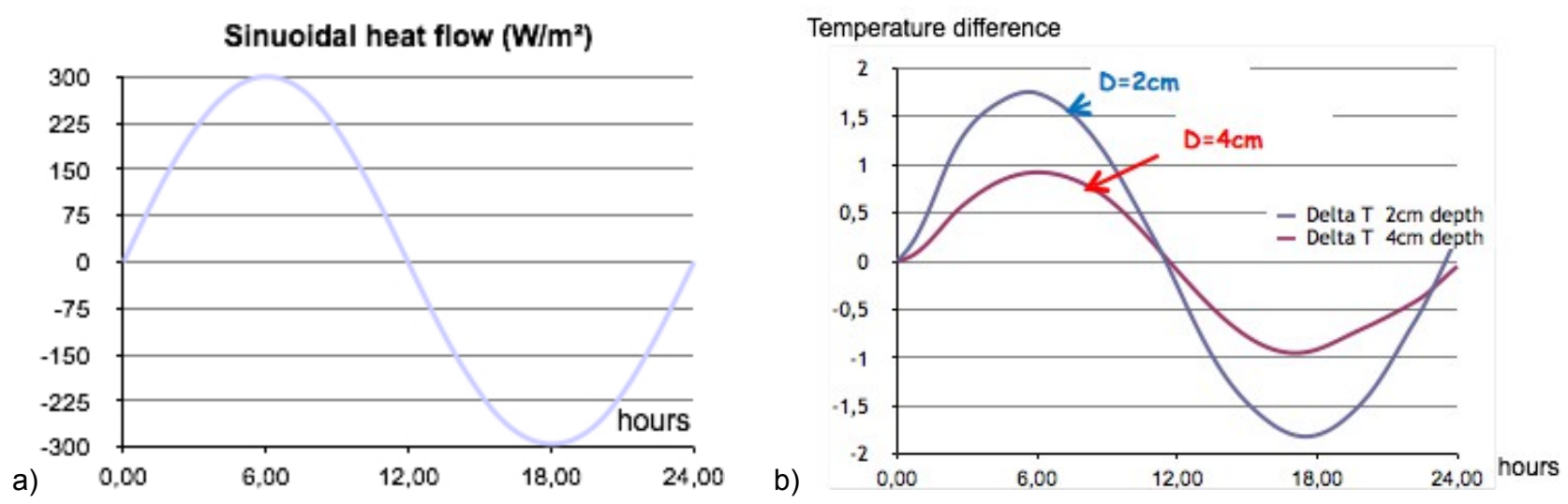

Fig. 10. a) Sinusoidal heat flow on 24 hours, b) Difference between the temperature on a defect area and an intact area for defects at $2 \mathrm{~cm}$ depth (in blue) and $4 \mathrm{~cm}$ depth (in red).

\subsection{Experiment on test slabs}

Infrared thermography tests were performed outdoor on the test slabs by passive thermography. The thermal stimulation is made by the climatic environment: solar radiation and convection. The sides have been insulated with foam to reduce heat losses from outskirt. The experimental set up is presented in Fig. 11.
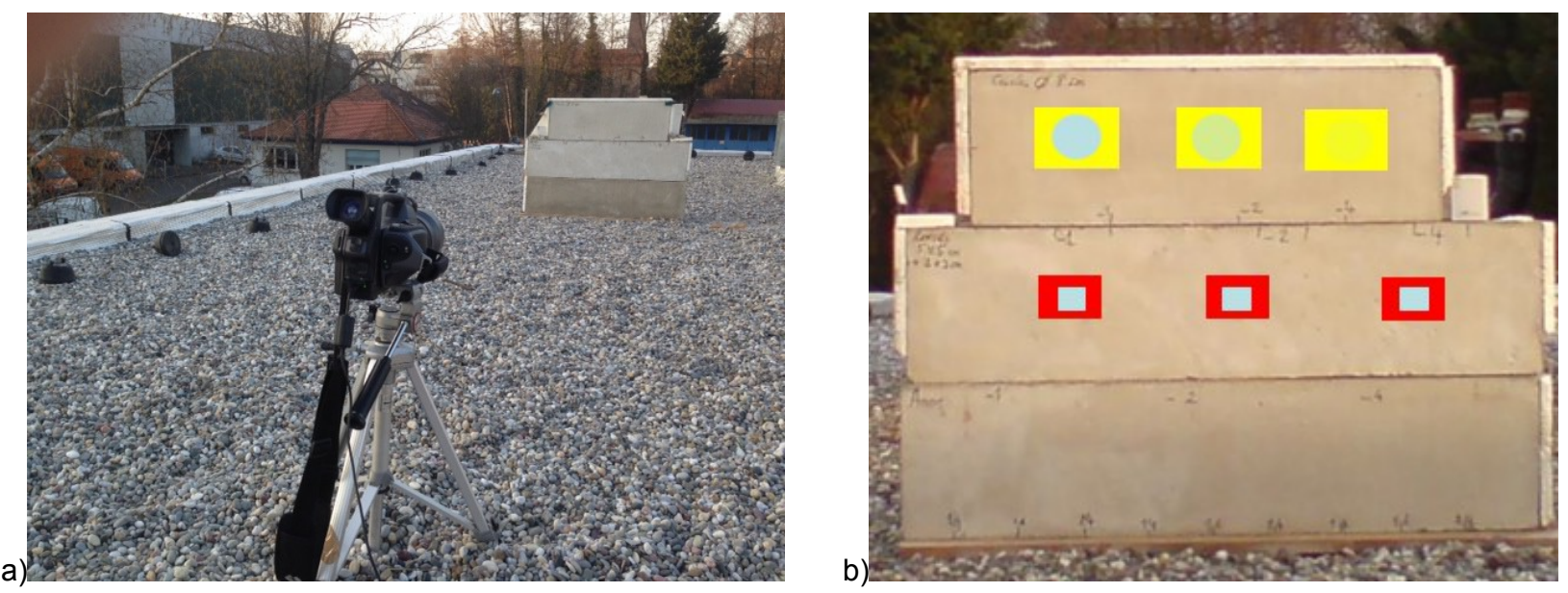

Fig. 11. (a) View of the experimental device, (b) Location of defects are highlighted in blue in the samples.

Images were taken every ten seconds by the infrared camera from $7.30 \mathrm{am}$ to $6.00 \mathrm{pm}$. An example of an image grabbed by the infrared camera can be seen in Fig. 12. Temperatures differences between defect areas and an intact one have been represented for the 3 defects. The results are presented in the Fig. 13.

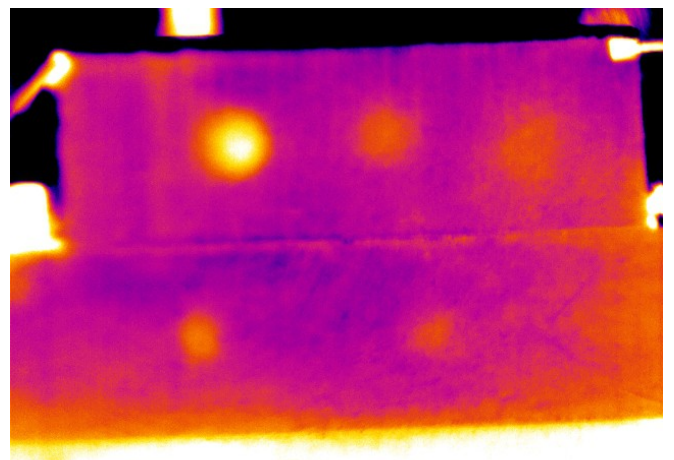

Fig. 12. Infrared image of the sample under natural solar stimulation. 

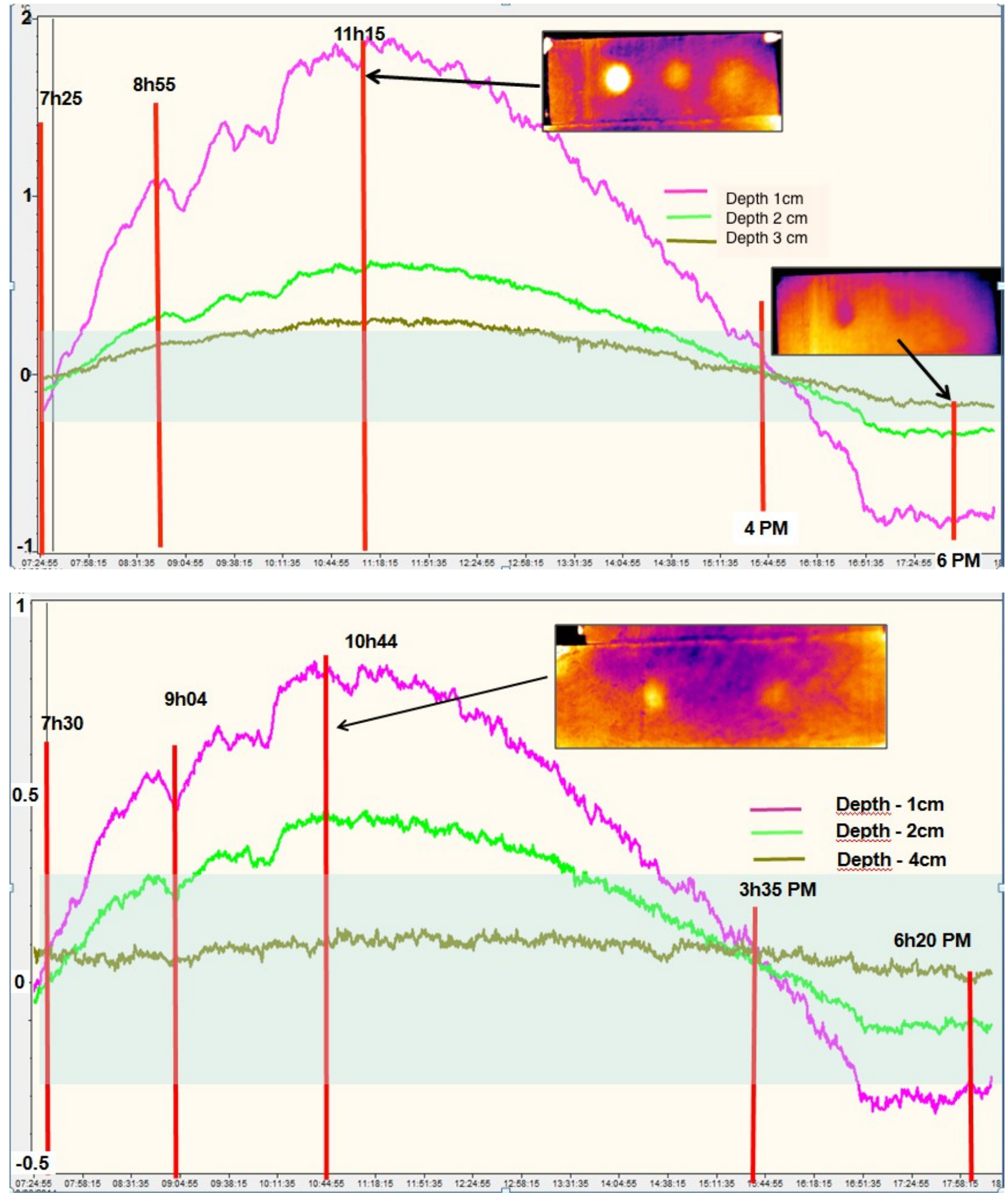

Fig. 13. Temperature differences between areas with defects on three different depths and an intact area: a) Circular defects of $8 \mathrm{~cm}$ diameter, b) $5 \times 5 \mathrm{~cm}$ squares defects.

While the defects closer to the surface could be quickly identified after the first sunlight exposure, the $4 \mathrm{~cm}$ depth defect was only detected when the ambient temperature increased. Whatever the depth, defects with a size of $2 \times 2 \mathrm{~cm}$, 
were never detected. Therefore we also tried to detect the $2 \times 2 \mathrm{~cm}$ defects in the laboratory with an active stimulation (infrared lamp and thermal cover) without any success.

\subsection{Experiment on a reinforced concrete bridge}

The experiment conducted on the test slabs has shown the applicability of the method and has defined the size and the depth of defects that could be detected.

Several experiments were conducted on reinforced concrete bridges in order to identify damaged cornices. To keep the operators safe, the experiments were performed with a camera equipped with a telephoto lens. As it can be seen on the Fig. 14, during the intervention, the road traffic was not stopped.

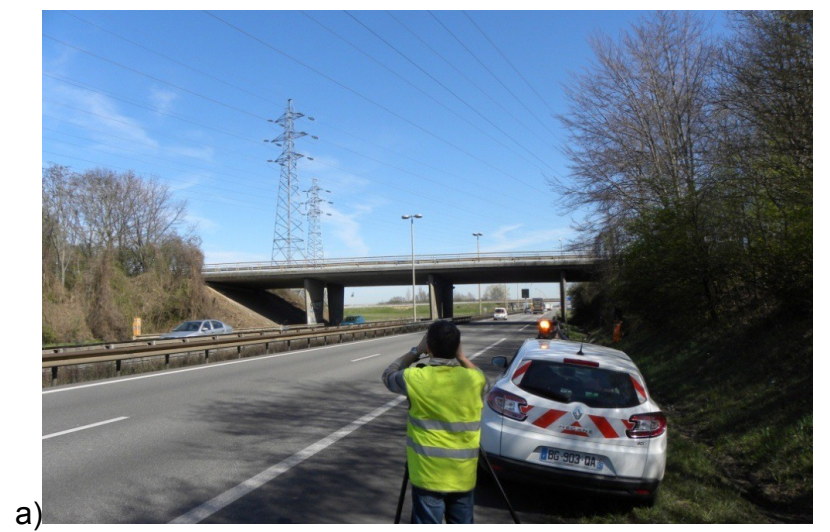

Fig. 14. Pictures of the camerawork ( $a$ and b) and implementation of shooting (c).
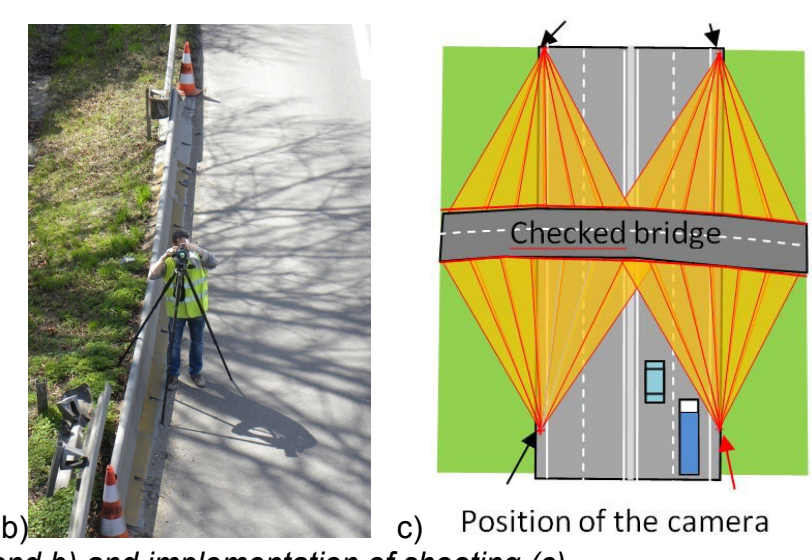

c) Position of the camera

To be able to localize defects, a bridge preparation is needed, for example by the placement of landmarks on the bridge as shown in Fig. 15. These landmarks should appear in infrared and visible spectrum. With this setup, it was possible to make a complete inspection of the cornices of the bridges with 4 installations of the camera. Several defects like delaminations were detected even in case of indirect sun exposure.

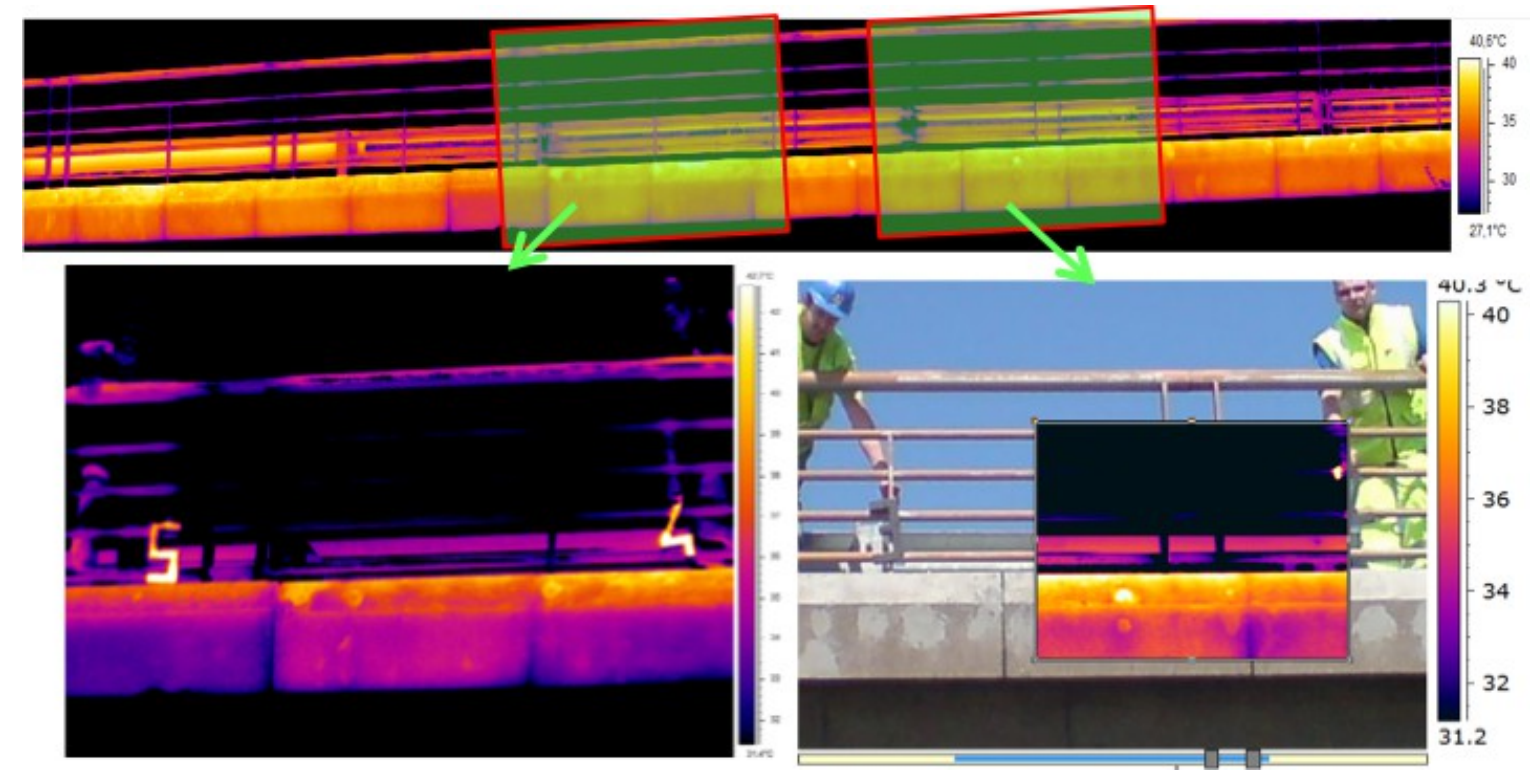

Fig. 15. Images of landmark (left) and defect detected in" fusion mode" (right). 


\section{Conclusions}

This study is a first approach to illustrate the interest of thermography in the evaluation of reinforced concrete bridges. It aimed to identify which size of defects and at which depth the infrared thermography could detect them. Smaller defects, under $4 \mathrm{~cm}^{2}$ were not detected but for larger ones, infrared thermography can be used up to $4 \mathrm{~cm}$.

Interventions in situ require efficient equipment, optimal weather conditions and time. A sunny day with a large thermal amplitude between night and day is optimal. A pre-visit for optimizing implantation sites shots and preparing landmarks is necessary.

This method remains a qualitative approach and do not allow to evaluate the depth of the defects and their effective size. Further works could aim to determine the depth of the defects by comparing the evolution of surface temperatures with those of a numerical model including defects.

\section{REFERENCES}

[1] "IQOA Ponts, Campagne d'évaluation 2011 - Dossier national ”, document SETRA 1221CD, juillet 2012

[2] "IQOA, Classification des ouvrages", document SETRA F9631, 1996

[3] O. Carpentier, F. Brachelet, D. Defer, C. Aubagnac, H. Cannard, "Characterization of defect under waterproofing layer by IR thermography and thermal impedance", NDTCE 2009, Nantes.

[4] Antczak E., Brachelet F., Carpentier O., Defer D., Rapport d'activité LAMTI 11N065 sujet 5 "Aide au diagnostic des chapes d'étanchéité par méthodes Thermiques".

[5] "Pathologie, diagnostic et réparation des corniches en béton armé", guide technique IFSTTAR, 2011

[6] Maldague X., "Theory and Practice of Infrared Technology for Non Destructive Testing", New-York, John-Wiley \& Sons, 2001

[7] ASTM D4788 "Standard Test Method for Detecting Delamination in Bridge Decks Using Infrared Thermography" standard

[8] Cannard H., "Autoroute A35 ouvrages $n^{\circ}$ 11b, 52, 53, 54 et 55, Examen des corniches par thermographie infrarouge", rapport d'intervention, 2013 